\title{
Factores que dificultam a transição dos alunos do segundo ciclo do ensino secundário para o ensino superior
}

\section{Factors hindering the transition of pupils in upper secondary education to higher education}

\author{
Maria Augusta César Nobre Gomes ${ }^{1}$, María Natalia Campos Soto ${ }^{2}$, Juan Antonio López \\ Núñez $z^{3}$ \\ ${ }^{1}$ Departamento de Enseñanza de Psicología, Universidade 11 de novembro, Angola (gomesnobre@ hotmail.com) \\ ${ }^{2}$ Departamento de Didáctica y Organización Escolar, Universidad de Granada, España (ncampos@ugr.es) \\ ${ }^{3}$ Departamento de Didáctica y Organización Escolar, Universidad de Granada, España (juanlope@ ugr.es)
}

\section{RESUMO:}

A transição dos alunos para outro ciclo do ensino é sempre uma situação que importa abordar.

É a partir do inicio do $2^{\circ}$ ciclo que o aluno apresenta maior diversidade no seu grupo de amigos, ajudando-o a desenvolver competências sociais e testar diferentes valores, contribuindo para o seu autoconceito.

O objectivo do presente artigo é a análise dos principais factores que dificultam a transmissão dos alunos do $2^{\circ}$ ciclo de ensino secundário geral para $o$ ensino superior, tendo como base de estudo os alunos em Angola.

Os resultados demonstraram que existe um conjunto de factores que influenciam e afectam a transição dos alunos para o ensino superior, tais como a gestão do tempo, a relação com os professores e o ambiente diferente.

\section{PALAVRAS-CHAVE: \\ EDUCAÇÃO, COMPETENNCIAS SOCIAIS, TRANSIÇAO ENSINO SECUNDÁRIO-ENSINO SUPERIOR, FACTOR TEMPO.}

\section{ABSTRACT:}

The transition of students to another cycle of education is always a situation that needs to be addressed.

It is from the beginning of the second cycle that the student presents greater diversity in his group of friends, helping him develop social skills and test different values, contributing to his self-concept.

The aim of this article is to analyze the main factors that make it difficult for students from the 2 nd cycle of general secondary education to higher education in Angola.

The results showed that there are a few factors that influence and affect students' transition to higher education, such as time management, the relationship with teachers and the different environment.

KEYWORDS: EDUCATION, SOCIAL SKILLS, TRANSITION FROM SECONDARY TO HIGHER EDUCATION, TIME FACTOR.

\section{INTRODUÇÃO}

A maior parte da literatura sobre as transições de ciclos, tem afirmado repetidamente que os alunos lutam com o tempo, e com outras exigências de gestão do ensino superior.

É a gestão de tempo que é considerada como o elemento mais importante das competências pessoais que os estudantes trazem para o ensino.

É observado que a avaliação subjectiva das habilidades de gestão de tempo, tornaram os resultados questionáveis e, cada vez mais, é necessário à sua análise. Inicialmente, uma análise Trueman e Hartley (1996) indicou que a gestão do 
tempo é maior no sexo masculino e, que os alunos mais maduros demonstraram melhores habilidades de gestão de tempo do que os outros grupos de estudo.

Posteriormente, o estudo efectuado por Goldfinch e Hughes (2007) demonstraram que um dos factores mais significativos para explicar o sucesso no primeiro ano, foi a alta confiança inicial nas habilidades de gestão de tempo, auto-suficiência e trabalho de equipa.

Da mesma forma, Jacklin e Robinson (2008) descobriram que a gestão do tempo e a comunicação assertiva, são competências significativas do sucesso académico na transição para o ensino superior.

\subsection{Competências da transição dos alunos que passam para o ensino superior}

Outro aspecto da transição que foi referido como desafiador inclui a participação (Lejk et Wyvill, 1999; Lopez-Real e Chan, 1999). Apesar dos desafios do trabalho em grupo, tanto Garvin et al. (1995) e Bourner, Hughes e Bourner (2001) referem que representa uma técnica de aprendizagem apropriada para o uso com os alunos em transição para outros ciclos de estudo.

Existe uma ampla literatura sobre os tipos de estilo / abordagem de escrita usados por alunos do primeiro ano e, esta abordagem muda ao longo do ensino superior, embora haja relativamente poucos artigos sobre como os alunos lidam com essa mudança. Hughes e Krause (2001) explora os desafios que os alunos encontram no ensino superior, seja através de trabalhos escritos ou outro tipo de avaliações. É por isso importante, a análise do impacto que estes apresentam na integração académica no ensino superior.

Não obstante, o desafio da transição revelou-se importante por um conjunto de outros factores, muitas vezes, ocorridos em paralelo, tais como a falta de informação inicial precisa sobre os componentes do curso, normas e requisitos; pobres escolhas do curso pelo aluno / falha em obter a primeira escolha nos cursos; expectativas irrealistas quanto à quantidade de trabalho e tempo envolvidos (Collier e Morgan, 2008).

Gale e Parker (2014) e Quesada-Pallarés, Fernández-de-Álava e Gairín (2017) argumentam que o ensino superior deve ser adaptado para ir de encontro às necessidades dos estudantes.

Outras obras importantes nas áreas de transição são Marland (2003); Brinkworth, McCann, Matthews e Nordström (2009); Krause, Hartley, James e McInnis (2005) e Thomas (2012).
Outro exemplo é o estudo de Byrne e Flood (2005) sobre a análise da realidade educativa irlandesa. Os autores analisaram as percepções dos alunos do primeiro ano de estudos do curso de contabilidade numa universidade irlandesa. De acordo com os autores, embora a maior parte dos alunos se sinta bem preparados com a transição, estavam confiantes na sua capacidade de lidar com os conteúdos da universidade.

Os alunos também indicaram baixas expectativas quanto ao comprometimento. As conclusões recomendam que os educadores comuniquem essas expectativas mais claramente desde o início do primeiro ano.

Um outro papel seminal no contexto irlandês é por Moore (2010) que examina as experiências de estudantes do primeiro ano de Geografia numa Universidade Irlandesa. $\mathrm{O}$ artigo conclui que a principal barreira na transição estudantil foi a falta de interacção social entre os alunos, que foi exacerbada.

No contexto da geografia (à luz do aumento do número de alunos) devido à incapacidade de trabalho de campo bem- sucedido. Os autores também observam que os alunos de primeiro ano, rapidamente se sentem desconectados e isolados, levando à falta de sucesso.

$\mathrm{Na}$ análise da transição dos alunos do ensino geral ao ensino universitário, o impacto dos conhecimentos das características académicas estruturais da instituição e o envolvimento do aluno (Rico-Romero, Gómez-Gúzmán e CañadasSantiago, 2014) parece ter efeitos positivos. Embora nas últimas décadas, a investigação sobre os estudos vocacionais segundo Teixeira (2009) tem demonstrado a influência das crenças de competência pessoal no sucesso académico, no desenvolvimento dos interesses, no esforço, na satisfação, e no nível das aspirações dos adolescentes (citado por Taveira, 2011). Numa perspectiva interactiva, para Taveira (2011) têm uma natureza integrativa e preconizam que a satisfação de vida é influenciada pelas variáveis de personalidade, pelas competências percebidas, pelos recursos e apoio do ambiente. Porém, no comportamento vocacional a perspectiva sociocognitiva funciona como uma das forças mobilizadoras da acção, no desenvolvimento dos interesses, das escolhas, e do desempenho académico com o reconhecimento, do apoio de ordem social, a importância do papel da família, e a importância dos professores como orientadores específicos para esses casos especiais de transição do ensino médio ao ensino superior. Toda via, este 
processo é facilitado quando o jovem conta com os contextos relacionais prévios e os pais estão disponíveis para responder às necessidades académicas e profissionais.

\subsection{Modelos de aplicação na avaliação da qualidade nos serviços públicos e privados}

O ensino superior está associado com a ideia de uma universidade, e a educação politécnica com a formação profissional e técnica. É necessário considerar como as instituições têm respondido às expectativas de mudanças e necessidades da sociedade ao longo dos últimos anos, como um preambulo para a compreensão da situação actual e as pressões enfrentadas pelas instituições contemporâneas e, pela razão de existir uma divisão binária no ensino.

O principal desafio da educação superior resumese à questão da diversidade. Tornou-se claro que o aumento do número de estudantes foi notório ao longo das últimas décadas e, que a este aumento, os países lidam de forma diferente. Muitos países, como o Reino Unido e a Alemanha, optaram por um sistema binário no ensino superior, proporcionaram uma educação com orientação mais profissional.

$\mathrm{Na}$ maioria dos países europeus as qualificações são equivalentes nas universidades e politécnicos, embora com a distinção de diversidade horizontal e diversidade vertical. A diversidade horizontal significa que existem diferentes tipos de instituições com a sua própria missão e perfil, mas semelhantes no quadro do ensino superior. A diversidade vertical refere-se a uma hierarquia das universidades, onde a diversidade é interpretada como melhor ensino de qualidade.

No entanto, o objectivo e metas são semelhantes lidar com a diversidade dos alunos e propor programas de ensino mais curtos. Como exemplo, a França oferece nas suas universidades programas de quatro anos que preparam os alunos para um grau de bacharel profissional, podendo integrar programas de dois anos seguintes a esta formação, que conduz a um diploma nacional em tecnologia especializada.

$\mathrm{Na}$ Inglaterra e Reino Unido existe um sistema de ensino superior unitário, após a fusão do sector politécnico com o sector universitário em 1992. O número de universidades tem aumentado posteriormente e, oferecem programas orientados para graus profissionalizantes, menos prestigiosos no mercado de trabalho. Neste país, somente as universidades com melhor desempenho recebem financiamento através do regime Research Assessment Exercise. Além de que, as novas universidades assumiram liderança no desenvolvimento de novas ofertas curriculares nas áreas de estudo da média e ciência do desporto, que se tornaram as escolhas mais populares e em expansão.

A democratização apresenta sim um carácter multidimensional e temporal. De acordo com Sebastião e Correia (2009) esta problemática está associada a questões da universalização da educação. De acordo com os autores, o processo de universalização constitui uma "das concretizações mais significativas da modernização das sociedades" (p. 101).

Em Angola, ao longo das últimas décadas o ensino superior e o mercado de trabalho seguem caminhos antagónicos, isto porque, o número de diplomados cresce de ano para ano, e pelo contrário, as oportunidades de ingresso no mundo do trabalho diminuem.

As instituições de ensino superior estão alheias a esta realidade, e por isso verifica- se uma oferta sistemática de cursos, em diversas instituições, que anualmente, impingiram para o mercado de trabalho um número de diplomados desproporcional às necessidades deste novo mercado.

Nas últimas décadas, a investigação tem demonstrado a influência da orientação vocacional e das tutorias no desenvolvimento profissional (Martínez-Clares, Pérez-Cusó e González-Morga, 2019; Pérez-Navío, Medina-Domínguez e CachónZagalaz, 2019; Solaguren-Beascoa, Fernández e Moreno-Delgado, 2016) na selecção e adaptação de novas actividades. De acordo com Rascovan (2013) a concepção actual de orientação vocacional, vem a substituir o esquema tradicional e reducionista que limitava a orientação a um serviço exclusivo para os indivíduos com problemas, baseado na relação interpessoal clinica, e num mero serviço de orientação profissional. Num passado, não muito remoto, os serviços de orientação vocacional não eram valorizados e em muitas ocasiões os indivíduos eram forçados ou encaminhadas a frequentarem formações não desejadas e, sem predisposição individual. No contexto atual a orientação segundo Valério (2012) se concebe como um conjunto de actividades preventivas, e atenção aos sujeitos no decorrer da sua formação que integra todos agentes sociais.

De acordo com Valério (2012) o conceito de orientação, suas funções e o modo de planificação foram desde o começo, imprecisos, problemáticos, e, com muita frequência, contraditórios. Segundo o mesmo autor a orientação tem sido tratada desde diversos enfoques: como processo que ajuda a 
pessoa a tomar decisões vocacionais, como forma de assessorar o indivíduo para resolução de problemas pessoais e sociais, como modelo de intervenção que brinda assistência ao sujeito e mais recentemente como ele atravessa o currículo. O papel da orientação esta também relacionado com a procura de soluções mais criativas relativamente à qualidade de formação pretendida, incluindo estratégias orientadas face à melhoria das competências e do interesse individual. $\mathrm{O}$ nível de qualificação do indivíduo funciona grandemente como consequência vocacional relacionada ao interesse primeiro individuais e a seguir sociais, para melhorar a capacidade de aprendizagem face as actividades profissionais, é necessário a existência da prédisposição, interesse individual considerado facilitador, da existência de uma cultura de aprendizagem profissional. Em diversos contextos da transição profissional, a orientação tem um impacto positivo. Não obstante, existe um longo caminho espinhoso a percorrer em termos de transição e manifestação das qualificações, desta forma sem sombra de dúvidas, o reconhecimento, validação e certificação da orientação profissional vincará. Neste caso a associação entre os interesses profissionais e auto-eficácia, para as actividades ocupacionais será insuficiente, complementando-se com a corroboração das actividades de orientação. $\mathrm{O}$ orientador é responsável pela organização dos interesses dos alunos, no que diz respeito a pessoa, que implica dirigir os seus esforços, motivá-las, controlar suas acções e se preciso modificar os seus comportamentos, para adequá-los as necessidades da sociedade. Sem essa intervenção de orientação os alunos seriam passivos e resistentes as necessidades de organização pessoal, a orientação é também utilizada como um mecanismo de persuadir, recompensar, controlar e dirigir as acções adequadamente.

\subsection{O ensino superior em Angola, contextualização}

A República de Angola é um país situado na África Austral, ocupa uma área de $1.246 .700 \mathrm{~km}^{2}$.

É um país plurilinguístico, onde o português é a língua oficial e de comunicação entre os angolanos, apesar de existirem outras línguas nacionais. $\mathrm{O}$ cristianismo é a religião que mais abunda no seio da população. $O$ ensino formal é feito em língua portuguesa. Segundo estimativas das Embaixada de Angola (2016) Angola contava com uma população de 8.989.000 habitantes em 1996, a densidade demográfica foi estimada em 7,2 habitantes por $\mathrm{km}^{2}$, a taxa de crescimento anual da população foi de
1,9\% calculada para o período de 1960/1970 e estimada em 2,8\% em 1985/1990. Aproximadamente, $31 \%$ da população estava concentrada nas zonas urbanas, devido a insegurança nas zonas rurais. Porem, dados demográficos mais actualizados, apresenta uma população estimada em 1.460.200, em 2002.

Potencialmente muito rico em recursos naturais, tais como petróleo, diamante, ferro e outros mineiros, dispõe de boas condições para o desenvolvimento agrícola, pecuário e florestal. É de salientar que depois da independência surgem os momentos da guerra civil, uma constante desestabilizadora, dando origem a um empobrecimento do estado, das populações e da já escassa rede escolar, elevando o índice de analfabetismo. Mas sem sombra de dúvida Angola é um lindo País com uma população conhecida pelo seu carácter, rigor, coragem e heroísmo. Que apesar das suas riquezas e potencialidades, o país atravessou uma crise económica provocada, principalmente, pela situação da guerra civil, sem esquecer da gestão a que estes recursos foram expostos (Zassala, 2003).

Com a participação de Angola no fórum Mundial de Educação realizada em Dakar (Senegal) de 26 a 28 de Abril do ano 2000 sob auspício da comunidade internacional ao adoptar o quadro de Acção Mundial para todos, constitui referência paradigmática mundial ao definir os objectivos, estabelecer as medidas e acções e ao fixar as metas nucleares para a concretização em todo o mundo uma educação pública de qualidade obrigatória para todos até ao ano 2015. O estado angolano ciente da sua responsabilidade na prossecução das deliberações do Fórum Mundial de Educação e baseado na realidade objectiva nacional, aprovou naquela época dois instrumentos normativos reitores, sendo a Lei de Bases de Educação e a Estratégia Integrada para Melhoria do Sistema de Educação no sentido de formular políticas educacionais de inclusão e projectar modalidades educativas diversificadas, currículos escolares flexíveis, tendo em vista as iniciativas educativas formais, não- formais para atender as necessidades de todos Porem, o governo da República de Angola com adopção do presente Plano de Acção nacional de Educação para todos 2001-2015, privilegia o asseguramento e o reforço dos serviços básicos sociais para as populações mais vulneráveis e desfavorecidas objectivando contribuir para redução dos níveis atuais de pobreza absoluta, com o compromisso internacional e de emergência do país situar-se no contexto dos padrões educacionais de 
qualidade universalmente aceites. Com o cumprimento dos seis objectivos estratégicos postulados pelo Fórum Mundial de Educação (2010):

1. Expandir e melhorar, em todos os aspectos, a protecção e educação na primeira infância, especialmente para as crianças mais vulneráveis e desfavorecidas;

2. Assegurar que, antes do ano 2015 todas as crianças e, sobretudo, as meninas e as em situação difícil e pertencentes a minorias étnicas, tenham acesso a um ensino primário gratuito, obrigatório de boa qualidade e o concluam;

3. Responder às necessidades de aprendizagem de todos os jovens e adultos, através do acesso equitativo a uma aprendizagem adequada e a programas de preparação para vida activa;

4. Aumentar em 50\%, até ao ano 2015, o número de adultos alfabetizados, em particular mulheres, facilitando a todos os adultos, um acesso equitativo à educação básica e à educação permanente;

5. Eliminar disparidade de género no ensino primário e secundário, até ao ano 2015 e alcançar, antes de 2015 a igualdade entre os géneros na educação, garantindo às meninas um acesso pleno e equitativo a uma educação básica de qualidade, com as mesmas possibilidades de sucesso;

6. Melhorar todos os aspectos qualitativos da educação, garantindo resultados de aprendizagem reconhecidos e mesuráveis, especialmente em leitura, escrita, cálculo e habilidades práticas essenciais para a vida.

Em África, a universidade representa uma instituição que detém ainda raízes culturais muito antigas.

A primeira universidade surgiu no Cairo, designada por Universidade de Al-Ahzar, em 1988 e, num período anterior, algumas universidades europeias como a de Bolonha (1088), Paris (1150), Oxford (1167) e Montpellier (1181). A Universidade de Al-Ahzar do Egipto oferecia cursos de: Agricultura, Engenharia, Estudos Dentários, Farmácia, Ciências Fundamentais, Estudos Filosóficos, Corânicos e Islâmicos (Ki- Zerbo, 1972). A segunda instituição africana a surgir foi a Universidade de Sankoré, situada na cidade Maliana de Tombuctu, entre os séculos X e XII. Eram duas universidades reconhecidas pelo seu vigo intelectual.
Contudo, as universidades modernas em África foram criadas muito antes do período colonial, pelo que antes do ano de 1960, existiam somente 18 dos 48 países em África Subsariana.

De acordo com Makosso et al. (2009) foi após o ano de 1970 que se registou maior proeminência da universidade no contexto africano e, que poderá ser dividida em quatro momentos:

(a) a africanização dos postos dos professores e investigadores; (b) a expansão e a multiplicação dos estabelecimentos de ensino; (c) a elaboração dos novos quadros estatutários; (d) a criação de órgãos destinados a orientar as políticas nacionais. (p. 1)

A este propósito Julius Nyerere, primeiro presidente da Tanzânia independente, afirmava:

A educação em África, em qualquer nível deve inculcar um sentido de compromisso com a comunidade e ajudar os alunos a aceitar os valores apropriados para o futuro, dandolhes o pensamento crítico e maturidade suficientemente razoável para a realização das suas actividades futuras com competência (Enciclopedia biográfica en línea, s.f.)

De salientar que, factores como o capital humano e a automatização podem assim, contribuir para a formação da capacidade intelectual tendo como base a internacionalização do conhecimento científico. É por esta razão que o Ensino Superior em África enfrenta ainda grandes desafios, em decorrência da necessidade constante e aos baixos níveis de resposta. Apesar destes aspectos, o Ensino Superior em África é reconhecido como uma força importante para a modernização e o desenvolvimento do país.

Em adição a estes aspectos, de acordo com o Banco Mundial (2010) as projecções relatam que a população jovem de África irá registar um rápido crescimento e, prevê- se que se dê um maior alargamento do acesso aos níveis de educação inferiores e mantenha uma tendência de crescimento no ensino superior. Sendo que Angola não estará alheia a esta tendência, poiscomeçam a despontar tendências nesse sentido (Angola National Commission, 2003).

A percentagem da população adulta sem instrução é estimada em 30 por cento. Dado que quase metade da população angolana é inferior a $14 \%$, a necessidade na oferta educacional é urgente. Muitos jovens mais velhos nunca entraram no sistema escolar nacional, ou se matricularam em escolas, não puderam continuar. Esta situação dificulta a sua integração económica enquanto 
adultos num local de trabalho caracterizado por mudanças rápidas, competição dura e exigências de habilidades elevadas. Também torna quase impossível para eles sair do círculo vicioso da pobreza extrema (United Nations Development Programme, 2011).

Face a crescente população estudantil, formada nas escolas do ensino secundário geral, inúmeras são as consequências negativas originadas pela fraca integração social dos jovens. Considerando também a crescente exigência em todos os campos sociais, no ensino superior e no mercado de emprego, que são cada vez mais valorizadas é nossa intenção, esmiunçar algumas consequências nefastas provocadas pela dificuldade no percurso de transição dos alunos, que têm como competência académica o ensino médio geral e que pretendem enquadrar-se ao ensino superior ou au campo laboral.

Almeida, Guisande e Paisana (2012) admitem que para além dos aspectos cognitivos, também as dimensões pessoais e motivacionais se relacionam de forma significativa com o rendimento académico e profissional. Neste processo de transição que por sua própria natureza, constitui uma situação que coloca grandes desafios, é imperioso que as dimensões do fórum pessoal e motivacionais estejam de certa forma ajustadas, para que tal processo venha a decorrer de forma satisfatória. O contrário acarreta nefastas consequências que afectam as dimensões pessoais e sociais.

Em suma, as consequências mais frequentes que encontramos neste processo conflituoso de transição, do ensino médio geral ao ensino superior ou ao mercado de trabalho, são as que passaremos a identificar nas linhas a seguir: são o desemprego, o vandalismo, a agressividade e a violência.

\section{MATERIAIS E MÉTODOS}

Os principais requisitos que dão suporte à parte teórica, são: reflectir sobre a transição dos alunos formados nas escolas do $2^{\circ}$ ciclo do ensino secundário geral; pensar em possíveis estratégias ou soluções como proposta para de minimizar a situação vivenciada pelos jovens; identificar algumas dimensões pessoais essenciais para um estudo/ profissional bem-sucedido.

Neste contexto o trabalho será desenvolvido, na escola do $2^{\circ}$ ciclo do ensino secundário geral em Cabinda, com a participação directa dos alunos da $12^{\mathrm{a}}$ classe, os professores da instituição e como não deixaria de ser também teremos como participantes os membros directivos da escola, dirigentes das instituições do ensino superior em Cabinda.
Determinou-se como objectivo geral: determinar quais os factores que dificultam a transição dos alunos do segundo ciclo do ensino secundário geral para o ensino superior.

As expectativas académicas funcionam como um filtro, através do qual os estudantes avaliam e dão sentido às suas vivências académicas, permitindo aos alunos definirem os domínios aos quais devem aplicar o seu esforço e dedicação (Almeida, Guisande e Paisana, 2012).

Pela sua relevância, envolvemo-nos na adaptação e validação do questionário de expectativas académicas:

- Determinar quais os principais factores que influenciam os resultados escolares dos alunos.

- Identificar quais os factores externos e internos que influenciam os resultados escolares dos alunos.

- Medir índices de sucesso académico e de qualidade de vida.

- Relacionar as vivências académicas dos alunos, o seu suporte social percepcionado, a sua integração social e índices de qualidade de vida e de sucesso académico.

- Estudar a relação entre as vivências académicas e as variáveis demográficas de cariz escolar

- Analisar a relação entre o suporte social e a integração social dos estudantes.

- Identificar se existem diferenças estatisticamente significativas entre os estudantes deslocados e os não deslocados no que concerne ao nível de personalidade.

Este estudo teve como objectivo adaptar o Questionário de Percepções Académicas: Versão E Expectativas (QPA-E), constituído por 62 itens, aos estudantes angolanos do Ensino Superior. Desde logo, tratando-se de um questionário em utilização em Portugal e Espanha, estando também em estudo no Brasil, importava verificar a relevância, clareza e compreensão dos itens junto destes estudantes em Angola.

\section{RESULTADOS}

Para cumprir os objectivos gerais e específicos, esta análise estatística investigação, vai determinar a relação de dependência entre certas variáveis e itens 
do questionário realizado. Isso nos permitirá fazer inferências profundas e esclarecidas, obtendo assim resultados mais rigorosos e coesos.

Entre as várias estatísticas que poderiam ter sido seleccionados através do teste de Mann-Whitney para variáveis dicotómicas e as variáveis polipotómicas Kruskal-Wallis; supondo um nível de confiança de 95\%. Portanto, considera-se a existência de diferenças estatisticamente significativas quando o valor $p<.05$. Eles escolheram estes testes não paramétricos como uma alternativa para os chamados t-Student e ANOVA como quando o teste para a eleição de uma análise ou outros requisitos de teste não foram obtidos.

Primeiro, consideramos o género dos professores não têm relação com a influência (nenhum, pouco, bonito e lotes) que dão as causas ou factores para o bom desempenho académico de seus estudantes (H0). Após a execução de estatística, verificou-se que a hipótese nula é rejeitada em oito dos itens que compõem a dimensão.

Observa-se que há uma dependência sobre a percepção dos professores sobre a influência sobre o sucesso de estudantes que se formam no estudo, de acordo com o sexo ( $p=0,004)$; também a influência dada ao grau de disciplina usuário depende de género professor $(\mathrm{p}=0,004)$; $\mathrm{a}$ influência dada à vontade para ter sucesso $(=0,000)$; a percepção da influência da capacidade intelectual $(\mathrm{p}=0,000)$, a saúde $(\mathrm{p}=0,000)$, a vontade de provar aos outros que é capaz ( $\mathrm{p}=, 041)$, a capacidade do professor para ensinar e explicação dos indivíduos $(\mathrm{p}=0,000)$ e saber que você quer no futuro, tanto formal e profissional $(\mathrm{p}=0,000)$.

Assumindo H0, o grau de concordância (concordo, concordo um pouco, acordar e concordam fortemente) do professor não depende do sexo em termos da reacção dos estudantes durante a transição dos alunos para o ensino superior, e depois da execução do teste de Mann-Whitney entre os sexos variando agrupamento $\mathrm{e}$ itens da nota dimensão que não são estatisticamente significativos professor diferenças de género e do grau de acordo sobre a itens "show alegria" ( $\mathrm{p}=, 000)$; "Show motivação" ( $\mathrm{p}=0,000)$ ); "Eles mostram muita motivação" ( $\mathrm{p}=0,000)$; "Show ansiedade" (006) e "show confiança em si mesmos" $(p=0,000)$. Para determinar quais variáveis contraste, há uma relação de dependência maior contamos com o valor $\mathrm{Z}$ e o grau de concordância dos professores, segundo a sua espécie, tem uma relação mais dependentes com "o aluno mostra autoconfiança" ( $Z=-6,444)$, "estudantes mostra um monte de motivação" ( $\mathrm{Z}=$ -
3,912), e "estudantes revela motivação" $(Z=-4,810)$ (Tabela 1).

Finalmente, quanto à dimensão das áreas que devem ajudar os professores a alunos, notamos que há diferenças estatisticamente significativas entre o grau de concordância por sexo e cinco das reivindicações. A relação de dependência mais próximo é dado ao "relacionamento com os professores" produto $(\mathrm{p}=0,001, \mathrm{Z}=-3,456)$, e "Métodos de estudo" ( $\mathrm{p}=0,003 ; \mathrm{Z}=-3,018)$. O resto tem sido a "gestão de recursos económicos" ( $\mathrm{p}=$, 027) e "avaliação da ansiedade" ( $\mathrm{p}=, 010)$.

\section{DISCUSSÃO DE RESULTADOS}

Em relação à amostra dos professores, a primeira dimensão que é exposta é uma das variáveis que pertencem aos dados demográficos da amostra. À primeira vista, podemos ver que a maior parte da amostra são homens em relação as mulheres, uma vez que o valor da moda é 1 , ou seja, a mais repetida também pelo baixo valor do desvio padrão indica uma distribuição a menos que haja dispersado, como o médio remanescente mais perto de um.

Como ocorre com a variável de referência para o curso de entrega dos valores das amostras do meio, a moda e o desvio padrão mostra que os participantes 95 reagiram da mesma maneira.

A soma dos valores das estatísticas descritivas que foram obtidas na análise dos itens que compõem a dimensão das causas ou factores que influenciam o bom desempenho dos alunos que ele ensina o ensino participante é exposto, de perspectiva.

Primeiro, sobre o interesse nos assuntos, observamos que os professores acreditam que esta tem uma grande influência sobre os resultados de alunos com $51,6 \%$ e os restantes $48,4 \%$ acham que este factor influencia muito. $\mathrm{O}$ interesse dos alunos nas disciplinas de estudo é altamente relevante para seu desempenho académico, e ter uma motivação intrínseca para o estudo da disciplina.

Sobre os vários factores que afectam ou influenciam o sucesso dos alunos afirma-se que os alunos pensam sobre se você terá sucesso, os professores percebem que é um factor muito influente $(63,2 \%)$ e $36,8 \%$ acham que é um elemento de grande influência.

Em segundo lugar, com base na preparação de exames em casa, observamos que $80 \%$ dos professores sustentou que este factor tem bastante influência sobre o bom desempenho; por sua vez, $20 \%$ indicam que é de grande importância para o sucesso escolar dos alunos. Vida académica do indivíduo está envolvido em dois contextos, tanto na 
escola como em casa. Além disso, novas tendências,

Em primeiro lugar, o grau de influência dado

Tabela 1. Estatísticas de teste Género

\begin{tabular}{|c|c|c|c|c|}
\hline \multicolumn{5}{|c|}{ Sua atitude face à transição dos estudantes para o ensino superio ${ }^{a}$} \\
\hline & $\mathrm{Ude}$ & Wilcoxo $n$ & $\mathrm{Z}$ & Significância Assint. \\
\hline & Mann-Whitne y & $\mathrm{W}$ & & (Bilateral) \\
\hline $\begin{array}{l}\text { Converso com eles (as) sobre o } \\
\text { assunto }\end{array}$ & 616,000 & 3619,000 &,- 831 & ,406 \\
\hline $\begin{array}{l}\text { Espero que eles (as) tenham a } \\
\text { iniciativa de tocar no assunto }\end{array}$ & 641,500 & 812,500 &,- 566 &, 571 \\
\hline Fico preocupado(a) & 520,500 & 691,500 & $-1,961$ &, $050 * *$ \\
\hline Fico ansioso(a) & 585,000 & 756,000 & $-1,782$ & 075 \\
\hline Fico animado(a) & 473,000 & 644,000 & $-2,83$ &, $005 * *$ \\
\hline $\begin{array}{l}\text { Estou sempre disponível para os } \\
\text { ajudar no que for necessário }\end{array}$ & 335,500 & 3338,500 & -4.539 &, $000 * *$ \\
\hline
\end{tabular}

De entre as dificuldades sentidas, quais as estratégias que considera que o supervisor pedagógico deve ter para ajudar o aluno (a) na transição para o ensino superior?

Criar para
$\begin{aligned} & \text { acompanhament o de orientação } \\ & \text { académica profissional nas escolas }\end{aligned}$
do ensino secundário

a. Variável de Agrupamento: Género

**. $\mathrm{P} \leq 0,05$

tais como a competência de ensino da educação afirmam que o aluno é o centro e o centro do processo ensino- aprendizagem, para que a aprendizagem auto-regulada e habilidades metacognitivas são fundamentais para o desempenho académico.

Em terceiro lugar, no domínio do assunto, repetindo a tendência dos itens já descritas, os professores afirmam que este elemento influencia muito $(63,2 \%)$, com $36,8 \%$ que atribuem muita importância.

Não se pode ignorar a capacidade intelectual a este respeito, mais de $70 \%$ da amostra disse que este factor influencia grandemente os resultados de sucesso dos alunos e quase $30 \%$ acham que o suficiente. pelos alunos sobre " materiais de juros de juros" depende da idade destes $(\mathrm{F}=2,966, \mathrm{p}=0,020)$, quanto maior $\mathrm{o}$ valor $\mathrm{F}$, maior a dependência entre as variáveis.

Em segundo lugar, quanto ao grau de influência de "a confiança / a" também depende da idade dos alunos $(\mathrm{F}=3,699 ; \mathrm{P}=006)$. Tendo em conta estas duas diferenças estatisticamente significativas, podese concluir que o segundo está mais intimamente relacionada com a idade do que a primeira $(\mathrm{M}=$ 3699> $\mathrm{F}=2,966$ ).

Com base nos itens que compõem a dimensão sobre os factores ou as causas que contribuem para o sucesso escolar e o grau de influência (nenhum, pouco, muito, muito) dada pelos alunos, é mostrado 
como tendo sido obtido sete relações de dependência.

Nós rejeitamos a hipótese nula "o grau de influência dado ao interesse nos assuntos como um factor que contribui para o sucesso académico é o mesmo, independentemente de alunos especiais", já que $\mathrm{p}=.000$, por isso há diferenças significativas.

\section{CONCLUSÕES}

A transição dos alunos do ensino secundário ou geral é acompanhada de um conjunto de atitudes e sentimentos. Os ambientes, os professores, as matérias e a forma de estudo são distintos. Este factor torna-se assim uma análise importante, seja através da perspectiva dos alunos como dos professores.

Transitar do mundo educativo ao mundo laboral constitui uma situação que coloca desafios e que requer, na maior parte dos casos, mudanças nos padrões de comportamento, exigindo ao indivíduo a mobilização dos recursos disponíveis para o sucesso e ajustamento possível entre si e as novas situações. Neste processo de transição dos alunos provenientes das escolas do segundo ciclo do ensino secundário geral, para o mercado de emprego, múltiplas exigências lhes são colocadas desde as competências, responsabilidades e desafios. Alem disso segundo Mesquita (2011) ao procurar responder as exigências profissionais, em constante evolução o projecto de formação pressupõe $o$ estabelecimento de parcerias com as escolas, como forma de assegurar as aprendizagens que ocorrem no contexto profissional.

Através da análise de campo foi possível determinar quais os principais factores que influenciam os resultados escolares dos alunos. Observou-se que os factores de maior influência são a relação com os professores, a gestão de tempo e a forma de estudo.

Analisando estes aspectos, pretendemos acreditar numa formação inicial sólida que comprometa o formando, a instituição formadora, os formadores e a sociedade considerados autores fundamentais deste processo tão relevante para o desenvolvimento do processo educativo com base na cultura comum de formação e de uma metodologia formativa que esteja adequada a cada realidade social, e cada vez mais centrada na formação de um profissional autónomo, criativo e responsável. Já não um mero técnico apenas por aplicar, de modo insensível à especificidade do contexto e da situação (Mesquita, 2011).
Como refere Mesquita (2011) as questões na formação inicial do formando assumem uma verdadeira importância. Sendo que as informações recentes complementam-se com as anteriores formando de certa uma representação real do que o aluno pretende como profissão. Neste enquadramento como refere Braga (2001) reforça que as perspectivas, os conceitos e as disposições com que os alunos chegam aos programas de formação influenciam em grande medida aquilo que eles aí aprenderão (citado por Mesquita, 2011).

\section{REFERÊNCIAS}

Almeida, L.S., Guisande, M. A., e Paisana, J. (2012). Extracurricular involvement, academic adjustment and achievement in higher education: A study of Portuguese students. Anales de psicología, 28(3), 860-865. doi: 10.6018/analesps.28.3.156231

Angola National Commission (2003). International Conference on Adult' Education. Recuperado de http://www.unesco.org/education/uie/pdf/country/Angol a.pdf

Banco Mundial (2010). Informe anual 2010. Recuperado de http://siteresources.worldbank.org/EXTANNREP2010S PA/Resources/BancoMundial-Informeanual2010.pdf

Bourner, J., Hughes, M., e Bourner, T. (2001). First-year Undergraduate Experiences of Group Project Work. Assessment e Evaluation in Higher Education, 26 (1), 19-39. doi: 10.1080/02602930020022264

Brinkworth, R., McCann, B., Matthews, C., e Nordström, K. (2009). First year expectations and experiences: Student and teacher perspectives. Higher Education, 58(2), $157-$ 173. doi: 10.1007/s10734-008-9188-3

Byrne, M., e Flood, B. (2005). A study of accounting students' motives, expectations and preparedness for higher education. Journal of Further and Higher Education, 29(2), 111-124. doi:10.1080/03098770500103176

Collier, P., e Morgan, D. (2008). Is That Paper Really Due Today? Differences in First Generation and Traditional College Students' Understandings of Faculty Expectations. Higher Education, 55(4), 425-446.

Embaixada de Angola (2016). Angola alcanza rendimiento medio alto. [Blog]. Recuperado de http://www.embajadadeangola.com/noticias/noticia210116-1.html

Enciclopedia biográfica en línea (s.f.). Biografías y vidas. [Blog]. Recuperado de https://www.biografiasyvidas.com/biografia/n/nyerere.ht $\mathrm{m}$

Fórum Mundial de Educação (2010). "Educación, Investigación y Cultura de Paz". [Blog]. Recuperado de http://omal.info/spip.php?article2354

Gale, T., e Parker, S. (2014). Navigating change: a typology of student transition in higher education. Studies in Higher $\begin{array}{llll}\text { Education, } & 39(5), & \text { 734-753. }\end{array}$ 10.1080/03075079.2012.721351

Goldfinch, J., e Hughes, M. (2007). 'Skills, learning styles and success of first- year Undergraduates'. Active Learning in Higher Education, 8 (3), 259-273. doi: $10.1177 \%$ 2F 1469787407081881

Garvin, J., Butcher, A., Stefani, A., Tariq, V., Lewis, N., Blumsom, R., y otros. (1995). Group projects for first 
year university students: an evaluation. Assessment \& Evaluation in Higher Education, 20(3), 279-94. doi: 10.1080/0260293950200304

Jacklin, A., e Robinson, C. (2007). 'What is Meant by 'Support' in Higher Education? Towards a Model of Academic and Welfare Support'. Journal of Research in Special Educational Needs, 7(2), 114- 123.

Hughes, S. C., e Krause, H. M. (2001). Establishment and maintenance of parasegmental compartments. Development, 128, 1109-1118.

Ki- Zerbo, J. (1972). Historia del África Negra. De los orígenes a las independencia. Casa África. [Blog]. Recuperado de

http://www.casafrica.es/coleccion_historia_politica_casa _africa.jsp.html

Krause, K.L., Hartley, R., James, R., e McInnis, C. (2005). The first-year experience in Australian universities: Findings from a decade of national studies. (Project). Higher Education University of Melbourne, Australia.

Lejk, M., e Wyvill, M. (1999). A survey of methods of deriving individual grades from group assessments. Assessment \& Evaluation in Higher Education, 21, 267- 280.

Lopez-Real, F., e Chan, Y.R. (1999). Peer assessment of a group project in a primary Mathematics Education. Assessment \& Evaluation in Higher Education, 24, 67-80.

Marland, M. (2003). The Transition from School to University Who prepares whom, when, and how? Arts and Humanities in Higher Education. 2(2), 201-211. doi: $10.1177 \% 2$ F1474022203002002007

Martínez-Clares, P., Pérez-Cusó, F. J., e González-Morga, N. (2019). ¿Qué necesita el alumnado de la tutoría universitaria? Validación de un instrumento de medida a través de un análisis multivariante. Educación $X X 1$, 22(1), 189-213. doi: 10.5944/educXX1.21302

Makosso, B., Safoulanitou, L.N., Ndeffo, L.N., Gbetnkom, D., N'guessan, J. F. C., KoffiRuffin, A.K., Thombet, M., e Gnamou, D. (2009). Enseignement supérieur en Afrique francophone. Crises, réformes et transformations. Dakar, Senegal: Codesria.

Mesquita, E. (2011). Competências do professor. Representações sobre a formação e a profissão. Lisboa, Portugal: Edições Sílabo.

Moore, N. (2010). Teaching for Better Learning: A Blended Learning Pilot Project with First-Year Geography Undergraduates. Journal of Geography in Higher Education, 34(3), 327-344. doi:10.1080/03098265.2010.501552

Pérez-Navío, E., Medina-Domínguez, M., e Cachón-Zagalaz, J. (2019). Perception of the Professional Competences of Last Year's Students of Pre-Primary Education and Primary Education Degrees and Students of Training Teachers Master. NAER Journal of new approaches in educational research, 8(1), 58-65. doi: 10.7821/naer.2019.1.344

Quesada-Pallarés, C., Fernández-de-Álava, M., e Gairín, J. (2017). ¿Cómo aprende el profesorado universitario español? Comprendiendo el uso de estrategias de aprendizaje. Revista de Educación, (376), 135-162. doi: 10.4438/1988-592X-RE-2017-376-347

Rascovan, S. (2013). Orientación vocacional, las tensiones vigentes. Revista Mexicana de Orientación Educativa, 10(25), 47-54.

Rico-Romero, L., Gómez-Gúzmán, P., y Cañadas-Santiago, M.C. (2014). Formación inicial en educación matemática de los maestros de Primaria en España, 1991-20101. Revista de Educación, 363, 35-59. doi: 104438/1988-592X-RE-2012-363-169
Sebastião, J. e Correia, S. V. (2009). The democratisation of school education in Portugal. En Leite-Viegas, J.M. e Carreiras, H. (Eds.). Portugal in the European Context, I. Institutions and Politics (pp. 101-126). Lisboa, Portugal: Celda Editora.

Solaguren-Beascoa Fernández, M., e Moreno-Delgado, L. (2016). Escala de actitudes de los estudiantes universitarios hacia las tutorías académicas. Educación XX1, 19(1), 247-266. doi:10.5944/educxx1.15586

Taveira, C. M. (2011). Estudos de psicologia vocacional. Coimbra, Portugal: Almedina, SA.

Thomas, L. (2012). Building student engagement and belonging in higher education at a time of change: a summary of findings and recommendations from the What works? Student retention and success programmed, Academy, T.H. E. Recuperado de https://www.heacademy.ac.uk/system/files/what_works_ summary_report_0.pdf

Trueman, M., e Hartley, J. (1996). A comparison between the time- management skills and academic performance of mature and traditional-entry university students. Higher Education, Berlim, 32(2), 199-215.

United Nations Development Programme (2011). Sustainability and equity: a better future for all. New York, United Nations Development Programme. Recuperado de http://hdr.undp.org/en/media/HDR_2011_EN_

Valério, M. (2012). Autonomia de profesores. Educar em Revista, 66, 327-332. doi: 10.1590/0104-4060.52325

Zassala, C. (2003). Orientação escolar e profissional em Angola. Luanda, Angola: Kulonga. 